\title{
Molecular study of patients with auditory neuropathy
}

\author{
GUILHERME MACHADO DE CARVALHO ${ }^{1}$, PRISCILA ZONZINI RAMOS ${ }^{2}$, ARTHUR MENINO CASTILHO $^{1}$, \\ ALEXANDRE CAIXETA GUIMARÃES ${ }^{1}$ and EDI LÚCIA SARTORATO ${ }^{2}$ \\ ${ }^{1}$ Otology, Audiology and Implantable Ear Prostheses, Ear, Nose, Throat and Head and Neck Surgery Department; \\ ${ }^{2}$ Human Molecular Genetics Laboratory, Molecular Biology and Genetic Engineering Center-CBMEG, \\ State University of Campinas (UNICAMP), São Paulo 13081-970, Brazil
}

Received August 10, 2015; Accepted January 20, 2016

\section{DOI: $10.3892 / \mathrm{mmr} .2016 .5226$}

\begin{abstract}
Auditory neuropathy is a type of hearing loss that constitutes a change in the conduct of the auditory stimulus by the involvement of inner hair cells or auditory nerve synapses. It is characterized by the absence or alteration of waves in the examination of brainstem auditory evoked potentials, with otoacoustic and/or cochlear microphonic issues. At present, four loci associated with non-syndromic auditory neuropathy have been mapped: Autosomal recessive deafness-9 [DFNB9; the otoferlin $(O T O F)$ gene] and autosomal recessive deafness-59 [DFNB59; the pejvakin $(P J V K)$ gene], associated with autosomal recessive inheritance; the autosomal dominant auditory neuropathy gene [AUNA1; the diaphanous-3 (DIAPH3) gene]; and AUNX1, linked to chromosome X. Furthermore, mutations of connexin 26 [the gap junction $\beta 2$ (GJB2) gene] have also been associated with the disease. OTOF gene mutations exert a significant role in auditory neuropathy. In excess of 80 pathogenic mutations have been identified in individuals with non-syndromic deafness in populations of different origins, with an emphasis on the p.Q829X mutation, which was found in $\sim 3 \%$ of cases of deafness in the Spanish population. The identification of genetic alterations responsible for auditory neuropathy is one of the challenges contributing to understand the molecular bases of the different phenotypes of hearing loss. Thus, the present study aimed to investigate molecular changes in the OTOF gene in patients with auditory neuropathy, and to develop a DNA chip for the molecular diagnosis of auditory neuropathy using mass spectrometry for genotyping. Genetic alterations were investigated in 47 patients with hearing loss and clinical diagnosis of auditory neuropathy,
\end{abstract}

Correspondence to: Professor Guilherme Machado de Carvalho, Otology, Audiology and Implantable Ear Prostheses, Ear, Nose, Throat and Head and Neck Surgery Department, State University of Campinas (UNICAMP), 251 Vital Brazil Street, São Paulo 13081-970, Brazil

E-mail: guimachadocarvalho@gmail.com

Key words: auditory neuropathy spectrum disorder, evoked auditory brainstem response, otoacoustic emissions, GJB2, hearing loss and the c.35delG mutation in the GJB2 gene was identified in three homozygous patients, and the heterozygous parents of one of these cases. Additionally, OTOF gene mutations were tracked by complete sequencing of 48 exons, although these results are still preliminary. Studying the genetic basis of auditory neuropathy is of utmost importance for obtaining a differential diagnosis, developing more specific treatments and more accurate genetic counseling.

\section{Introduction}

Hearing loss is the most prevalent sensory disease in humans; it is caused by a variety of genetic and environmental factors. Whereas environmental factors include exposure to frequent high-intensity sound, acoustic trauma, infections and ototoxic drugs, among others, genetic factors are caused by mutations in different genes or regulatory elements involved in the proper development, structure and function of the ear (1).

In developed countries, $>60 \%$ of all cases of hearing impairment result from genetic causes (2). However, in Brazil, environmental factors outweigh those of genetic origin $(3,4)$. Considering that improvements are being implemented in the health sector, and with the advancements being made in genetic studies associated with hearing loss, the proportion of genetic causes tends to increase.

International statistics reveal that one in every 1,000 newborns has hearing loss $(5,6)$. In Brazil, the frequency is estimated at four per 1,000 births (7). However, this often varies: Depending on the sample and study area, it may be present in 2-7 per 1,000 newborns (8).

Recent years have witnessed significant advances in research on the molecular basis of the auditory system, enabling the identification and characterization of several genes and proteins associated with hearing. The increasing knowledge about these genes contributes not only to an improved understanding of the mechanisms of hearing, but also to the molecular basis of hearing impairment. This basic research is a prerequisite for the development of molecular diagnostics and novel therapies for deafness (9).

One of the biggest obstacles in the search for genes involved in hearing loss is the difficult access to the cochlea and other inner ear structures. The construction of a cDNA library of fetal cochlear equipment allowed the issue of candidate genes to be addressed using a tissue-specific approach $(10,11)$. The 
large number of genes expressed in the cochlea reflects the complexity of the molecular mechanisms involved in this organ of intricate nature (12).

Most cases of hereditary hearing loss ( 70\%) are non-syndromic. Different loci or regions to submit candidate genes associated with non-syndromic deafness receive the prefix DFN (from deafness), followed by a number indicating the order in which they were discovered. The known genetic mutations that lead to deafness may be autosomal recessive (DFNB), autosomal dominant (DFNA), X-linked (X DFN) or mitochondrial (1,13-15).

Regarding the mechanisms of inheritance, it is estimated that $75-80 \%$ of cases of non-syndromic genetic deafness are autosomal recessive, $20-25 \%$ are autosomal dominant, and $1-2 \%$ are linked to the $\mathrm{X}$ chromosome. In addition, the frequency of mitochondrial inheritance is estimated at $1 \%(13-17)$.

The heterogeneity of non-syndromic autosomal recessive hearing loss is high, for which 71 loci have been described, and 40 genes have been identified to date (18).

Auditory neuropathy (AN) is a type of sensorineural hearing loss, consisting of auditory stimulus alteration as a result of the involvement of inner hair cells or auditory nerve synapses. It is characterized by the absence or alteration of waves in the examination of the brainstem auditory potential response in the presence of otoacoustic emissions and/or cochlear microphonism (19).

It is responsible for $7-10 \%$ of the cases of hearing loss in children, and may be caused by a number of genetic and environmental factors, including hyperbilirubinemia, prematurity, anoxia, exposure to ototoxic drugs and infections, among others. Regarding etiology, it is estimated that $\sim 42 \%$ of cases are hereditary, $10 \%$ are associated with toxic, metabolic, immunological and infectious factors (e.g. ototoxic drugs, anoxia, hyperbilirubinemia, demyelination and viral infections), and 48\% are idiopathic (20-22).

The AN may be associated with other disorders (syndromic) as part of the clinical signs of systemic neurodegenerative diseases, including Charcot-Marie-Tooth disease, Friedreich's ataxia, Guillain-Barré neuropathy and mitochondrial diseases, or there may be (non-syndromic) isolated clinical signs (2).

Given the peculiar characteristics of patients with AN, the treatment of these individuals is a challenge. There is a need to gain an improved understanding of the pathophysiology of this disease, and studies on genetic and molecular assessment can provide important collaboration. Over the course of the last decade, the identification of genes responsible for $\mathrm{AN}$ have contributed greatly to the diagnosis and improved understanding of the mechanisms involved in the disease.

The otoferlin (OTOF) gene is one of the 40 genes associated with autosomal recessive non-syndromic hearing loss. It is located in the locus DFNB9, chromosomal region 2p22-23. The gene contains 48 exons and encodes multiple isoforms of proteins generated via long and short alternative splicing events, combined by using different transcriptional initiation sites. OTOF is expressed in the cochlea, vestibule and brain, and is involved in the exocytosis of synaptic vesicles from inner hair cells (23-26).

Mutations in the $O T O F$ gene are responsible for a prelingual, fairly homogenous phenotype of profound hearing loss, without associated defects in the inner ear. However, numerous affected individuals have AN. Over 80 pathogenic mutations have been identified in individuals with non-syndromic deafness, in populations of different origins (27-29).

In 2004, another locus, AUNA1, was mapped in an American family, in the chromosomal region 13q21-q24, associated with autosomal dominant postlingual AN, and the corresponding gene, diaphanous-3 (DIAPH3), was subsequently identified $(30,31)$.

The $A U N X 1$ gene was mapped in 2006, a novel locus associated with $\mathrm{AN}$, although this time linked to the $\mathrm{X}$ chromosome in the Xq23-q27.3 region, in a Chinese family inheritance. The corresponding gene has not been identified (32).

More recently, another neuropathy associated with the autosomal recessive gene was identified. The gene PJVK (DFNB59), located in chromosome region 2q31.1-q31.3, encodes pejvakin (PJVK), a protein of the afferent auditory pathway involved in signaling from hair cells and neurons. However, mutations in this gene are not a frequent cause of $\mathrm{AN}$ in Brazil, as are mutations in the OTOF gene $(33,34)$.

Furthermore, mutations in connexin 26 [the gap junction $\beta 2$ (GJB2) gene] have also been associated with AN. Two different studies have identified cases with AN among individuals with hearing loss, who had mutations in the GJB2 gene $(35,36)$.

Currently, it is known that changes in connexin 26 interfere with the ionic homeostasis of the inner ear, leading to the accumulation of extracellular potassium, which results in cell death. Thus, it is likely that otoacoustic emissions observed in patients in the studies cited above represent residual activity of a few outer hair cells that remained alive in the apical part of the cochlea. However, it is considered that certain mutations in the GJB2 gene may cause changes in the inner hair cells and nerve endings of the hair cells $(37,38)$.

Therefore, further studies are required to clarify the association between AN and GJB2 gene mutations $(37,38)$. A previous study has also investigated connexins and gap junctions, such as one involving the gap junction $\beta 4$ (GJB4) gene (39), which may be associated with non-syndromic hearing loss.

There are several ways to detect changes and/or mutations in the genome and, recently, high-throughput technologies have emerged as an interesting alternative. Genotyping using the MassARRAY ${ }^{\circledR}$ system (Sequenom, Inc., San Diego, CA, USA) with the matrix-assisted laser desorption ionization time-of-flight mass spectrometric (MALDI-TOF MS) technique and iPLEX, termed Gold Assay ${ }^{\circledR}$, may be considered a powerful tool with an attractive approach. Genotyping is considered a method for obtaining an average yield, and allows the genotyping of up to 40 single nucleotide polymorphisms (SNPs) simultaneously, using 96-3,840 samples, quickly and at low cost $(40,41)$.

Allelic discrimination is achieved using MALDI-TOF MS, which has been widely used for analyzing multiplex products and different genotypes, based on differences in the molecular weights of nucleotides $(40,41)$.

Therefore, MS currently represents a powerful and versatile analytical method that provides valuable information about the composition and structure of molecules, and also sheds light on the quantity of specific analytes in mixtures. This method provides an attractive solution for the genotyping 
of SNPs, particularly since it allows direct and rapid DNA measurement, rather than only detecting a mark (radioactive or fluorescent), and the results may be easily analyzed by automated software $(40,41)$.

MALDI-TOF MS was first employed in 1988 by Karas and Hillenkamp (42) as a revolutionary method for the ionization and mass analysis of numerous biomolecules. These researchers demonstrated that irradiation of crystals formed by suitable small organic molecules (called matrix) with a short-pulse laser caused an energy transfer and desorption process, producing the matrix ions in the gas phase. Of even greater importance, they determined that, if a low concentration of a non-absorbent analyte, such as a protein or nucleic acid molecule, is added to the matrix solution and embedded in the solid matrix of crystals formed by drying the mixture, non-absorbent intact molecules of the analyte also would be sent to the gas phase and ionized laser, facilitating its mass analysis $(42,43)$.

The basic components of a mass spectrometer consist of an ionization source (UV laser), an analyzer and a detector. For analysis, the biological sample (nucleic acid mixture) is added to a material (matrix), usually a low-molecular-weight organic acid with a strong absorption at the laser wavelength in blocks of one silicon chip surface. The MALDI-TOF process is then initiated by laser desorption of an analyte-matrix mixture. Subsequent physical processes result in the predominant formation of either positively charged or negatively charged ions. These ions are extracted using an electric field, and separated according to their molecular masses and their charges $(40,42,43)$.

The masses of nucleic acid compounds are calculated using TOF, which reflects the time that the laser-ionized compound requires to be carried through the flight tube (1 to $2 \mathrm{~m}$ length) TOF analyzer and reach the instrument detector. At the detector, the ionized compounds generate an electrical signal that is recorded by a data system and is finally converted into a mass spectrum. The resolution of the current generation of MALDI mass spectrometers enables easy distinction of nucleobase replacements, with a mass variation of 1,000 to $7,000 \mathrm{Da}$, which corresponds to a DNA size from 3 to 25 nucleobases $(40,44,45)$.

The identification of genetic alterations responsible for AN is one of the challenges that contribute to the understanding of the molecular basis of the different serotypes of hearing loss phenotypes. Furthermore, the use of novel molecular tools that enable a more rapid and effective diagnosis is of great interest for these patients. Thus, these factors are important for a differential diagnosis, as well as for developing more specific treatments and a more accurate genetic counseling.

The present study aimed to investigate molecular changes of the OTOF gene in patients with $\mathrm{AN}$, and to develop a DNA chip for the molecular diagnosis of AN, using MS for genotyping, specifically: i) To investigate the presence of the mutation, c.35delG, and other changes in the GJB2 gene, the deletions $\operatorname{del}(G J B 6-D 13 S 1830)$ and $\operatorname{del}(G J B 6-D 13 S 1854)$ in the GJB6 gene, and the mitochondrial mutation $\mathrm{m} .1555 \mathrm{~A}>\mathrm{G}$ in the MTRNRl gene; ii) to determine the frequency of the p.Q829X mutation in exon 22 of the OTOF gene in Brazilian patients with $\mathrm{AN}$; iii) to check the occurrence of other genetic alterations by sequencing the complete OTOF gene; and iv) to standardize the method of genotyping using the MassARRAY ${ }^{\circledR}$, Sequenom system for molecular diagnosis of AN, with the predominantly occurring mutations in Brazilian and world populations.

\section{Materials and methods}

Clinical subjects. This study comprised 47 patients from a tertiary care center diagnosed with hearing loss and AN. All subjects underwent audiological evaluation, including pure tone audiometry, speech audiometry, tympanometry, otoacoustic emissions and brainstem auditory evoked potential.

Patients who presented an absence of, or alterations in, the waves in the examination of the potential auditory brainstem response in the presence of otoacoustic and/or cochlear microphonic issues were clinically diagnosed with AN.

Initially, patients underwent a clinical evaluation performed by ear, nose and throat doctors. Subsequently, blood samples were collected and forwarded directly to the Human Molecular Genetics Laboratory, Center of Molecular Biology and Genetic Engineering (CBMEG)-UNICAMP, where genetic tests were performed.

All patients in this sample had previously authorized their participation by signing the informed consent statement, having received clarification on the study to be performed. This project was approved by the Research Ethics Committee of the Faculty of Medical Sciences, UNICAMP (form number 96/2006).

Genomic DNA extraction from peripheral blood. The genomic DNA extraction was performed from leukocytes obtained from $10-15 \mathrm{ml}$ of peripheral blood collected in EDTA Vacutainer ${ }^{\circledR}$ tubes (BD Biosciences, Franklin Lakes, NJ, USA). The method of extraction with phenol and chloroform was used (46), standardized in the Human Molecular Genetics Laboratory of CBMEG.

Analysis of mutations in the GJB2 gene, deletions del(GJB6-D13S1830) and del(GJB6-D13S1854) in GJB6, and the mitochondrial mutation m.1555A $>G$ in the MTRNRI gene. The mutation c.35delG in the connexin 26 (GJB2) gene was screened by allele-specific polymerase chain reaction (PCR) using Amplification Refractory Mutations System ('ARMS') primers for the detection of point mutations (44). The normal (NOR) and mutant (MUT) primers were used in different reactions to amplify alleles with or without mutation, respectively. The common primer (COM) was used as the reverse primer (47). These two reactions (NOR and MUT) may be identified as being normal homozygote, heterozygote and mutant homozygote to mutation c.35delG in each individual. Primers A and B were used as internal controls for amplification reactions (47). This technique was developed in the Human Molecular Genetics Laboratory of CBMEG (patent no. P10005340-6, test method for deafness of genetic origin-UNICAMP, 2002).

Screening for mutations in the GJB2 gene by sequencing. The coding exon of the GJB2 gene, with $681 \mathrm{bp}$, was divided for amplification by technical PCR, according to a previously described protocol $(48,49)$. 
Purification of the PCR products. First, the fragments to be amplified by PCR were purified using the Wizard ${ }^{\circledR}$ SV Gel and PCR Clean-Up system kit (Promega Corp., Madison, WI, USA). The purification, quantity and purity of the DNA sample were determined by optical density in a spectrophotometer (NanoDrop ${ }^{\circledR}$ ND-8000; Thermo Fisher Scientific, Waltham, MA, USA).

Sequencing reaction. Sequencing reactions were performed in the automatic sequencer ABI PRISM ${ }^{\circledR} 3700$ DNA Analyzer, using the BigDye ${ }^{\text {TM }}$ Terminator v3.1 Cycle Sequencing kit (Applied Biosystems Life Technologies, Foster City, CA, USA), according to the manufacturer's protocol. The reactions consisted of 40-80 ng DNA, $1 \mu \mathrm{l}$ mix BigDye ${ }^{\circledR}$ and $1 \mu 1$ primer (5 pmol), adding deionized water to a final volume of $10 \mu \mathrm{l}$. The amplification conditions were: $96^{\circ} \mathrm{C}(1 \mathrm{~min})$, followed by 30 cycles of $96^{\circ} \mathrm{C}(10 \mathrm{sec}), 57^{\circ} \mathrm{C}(5 \mathrm{sec})$ and $72^{\circ} \mathrm{C}(30 \mathrm{sec})$, completing the cycle at $72^{\circ} \mathrm{C}(5 \mathrm{~min})$.

Analysis of the obtained sequences. The obtained sequences were smoothed and compared with normal gene sequences, using the programs Chromas Lite ${ }^{\circledR}$, Gene Runner ${ }^{\circledR}$ v. 3:01 and CLC Sequence Viewer 6.1 (CLC bio; Aarhus, Denmark) [see Technelysium 2012: http://www.technelysium.com. au/chromas_lite.html; and Generunner 2013: http:/www. generunner.net].

Identification of the deletions, del(GJB6-D13S1830) and del(GJB6-D13S1854), in the GJB6 gene. The tracking deletions, $\operatorname{del}(G J B 6-D 13 S 1830)$ and $\operatorname{del}(G J B 6-D 13 S 1854)$, were performed according to protocols previously described by Del Castillo et al $(50,51)$. The investigation of mutations was performed using a multiplex PCR protocol, searching for the presence of the two deletions in one reaction. Fragments resulted from the amplification of DNA containing the breakpoints of the two deletions, as well as a segment of exon 1 from the GJB6 gene, which was used as a control to check the efficiency of the reaction and to distinguish between heterozygous and homozygous alleles for either of the two deletions.

Screening of the mitochondrial mutation m.1555A>G in the MTRNRl gene. The conditions previously described by Friedman and Griffith (52) and Iwasaki et al (53) were used for tracking the m.1555A $>\mathrm{G}$ mutation $(15,52,53)$. Following amplification, fragments of mitochondrial DNA of $2060 \mathrm{bp}$ were generated, and subsequently subjected to restriction analysis using the restriction endonuclease BsmAI (New England BioLabs, Inc., Ipswich, MA, USA) for $2 \mathrm{~h}$ at $55^{\circ} \mathrm{C}$. Among individuals who were not carriers of the mutation $\mathrm{m} .1555 \mathrm{~A}>\mathrm{G}$, three fragments were generated of size 1,100, 516 and $444 \mathrm{bp}$, whereas in individuals with the mutation, one of the region restrictions was abolished, generating only two fragments, of 1,616 and $444 \mathrm{bp}$.

Detection of mutations in the OTOF gene. For mutation screening, detection of the mutation p.Q829X (c.2485C>T) in exon 22 of the OTOF gene was accomplished using the PCR- fragment length polymorphism technique [primers: $22 \mathrm{~F}$ (forward): 5'-TGACACCCCCTCCTTCGC-3' and 22R (reverse): 5'-CCCGACCCCTTGGGCGC-3']. Following amplification, the fragment of $157 \mathrm{bp}$ was digested with the enzyme BfaI (New England BioLabs, Inc.). In the presence of the mutation, the product was digested into two fragments of size 98 and $59 \mathrm{bp}$. The fragments were observed on a $3 \%$ agarose gel (Invitrogen; Thermo Fisher Scientific, Inc.) run at $100 \mathrm{~V}$ for $2 \mathrm{~h}$, following a protocol described previously (54).

Complete screening of mutations in the OTOF gene. Mutations in the $O T O F$ gene were tracked through the entire sequencing of exon 48, according to the protocol previously described by Migliosi et al (54). The sequencing steps were performed as described above for the GJB2 gene.

Genotyping using MS. Genotyping was performed using the MassARRAY® system of Sequenom, Inc. by MALDI-TOF MS, and the iPLEX ${ }^{\circledR}$ Gold Assay system.

Test definition. Capture oligonucleotides (amplification primers) and single-base extensions were drawn from selected mutations with and/or SNP sequences. The tests were performed using MassARRAY Assay Design ${ }^{\circledR}$ software (version 3.1; Sequenom, Inc.). This program also generates groups of SNPs (multiplex) to be evaluated together. As this is a platform for high level, there is the possibility of evaluating up to 40 SNPs, or changes simultaneously in a single reaction for a given sample.

Amplification products containing SNPs and/or mutations. After evaluating the mutations or SNPs, defined capture primers were used in amplification products ranging from 100 to $400 \mathrm{bp}$, encompassing the region with the polymorphic site. Amplifications were performed in a GeneAmp ${ }^{\circledR}$ PCR system 9700 (Applied Biosystems) thermocycler with two blocks of 384 sample plates, following the protocol described by Sequenom ${ }^{\circledR}$ (iPLEX Gold Application Guide).

At this stage, the fragments containing the changes are captured. Amplification reactions were performed in a final volume of $5 \mu \mathrm{l}$ containing $10 \mathrm{ng}$ DNA template, 10X buffer, $500 \mu \mathrm{M}$ each deoxynucleotide triphosphate (dNTP), $25 \mathrm{mM} \mathrm{MgCl}$, $500 \mathrm{nM}$ each primer and 5 units HotStar Taq DNA polymerase.

Treatment with SAP. After PCR, the amplification products have undergone a treatment for neutralization of unincorporated dNTPs, using the shrimp alkaline phosphatase (SAP) enzyme. The SAP inactivates dNTPs that have not been incorporated during the amplification reaction, converting them into non-phosphorylated nucleotides, and making them unviable for future dNTP reactions. To each sample, $2 \mu \mathrm{l}$ of the SAP reaction was added, and the plate was incubated in a thermocycler at $37^{\circ} \mathrm{C}$ for $45 \mathrm{~min}$ for enzyme action.

Reaction extension-iPLEX ${ }^{\circledR}$. Aliquots of $2 \mu \mathrm{l}$ of a cocktail of extension (iPLEX Gold reaction), composed of primer extension enzyme (iPLEX enzyme), buffer (10X iPLEX Plus Buffer) and nucleotides modified with masses (iPLEX Terminator Mix; Sequenom, Inc.), were added to the treated amplification products.

This reaction also occurred with the aid of the thermal cycler mentioned above. During the reaction, the primer 
was exactly of the correct length adjacent to the SNP site, extending only one base (single extended background process). The extended iPLEX Gold Reaction generates products of different masses, depending on the nucleotide that has been added, or depending on the allelic form present in this sample.

Cleanliness of reactions and MS. Prior to MS, the iPLEX reaction products underwent cleaning using a resin (Clean Resin; Sequenom, Inc.), which removes excess ions that can interfere with the reading laser. A total of $6 \mathrm{mg}$ resin was added to each of the 384-well plates, and $16 \mu 1$ water was added to the total volume to make a final volume of $25 \mu \mathrm{l}$ in each sample.

Reactions were transferred from the 384 plates to SpectroCHIP, with the aid of a MassARRAY Nanodispenser (Sequenom, Inc.). The SpectroCHIP was analyzed from the MassARRAY Compact Analyzer (Sequenom, Inc.) using the technique of MALDI-TOF MS.

The MALDI-TOF process was initiated by laser desorption of the analyte-matrix mixture and the analyte that the amplification product generated and selected during the iPLEX reaction. The subsequent physical processes result in the predominant formation of positively charged or negatively charged ions. These ions were extracted with an electric field, and separated according to their molecular masses and their charges.

The mass of the nucleic acid compounds was calculated using TOF, which reflects the time that the laser-ionized and accelerated compound requires to be taken through the tube (1-2 m length) of the analyzer and reach the detector of the instrument. At the detector, the ionized compounds generate an electrical signal that is recorded by a data system and is finally converted into a mass spectrum (45).

The MassARRAY TyperAnalyzer 4.0.5 software package was used to assimilate the information generated during the process described above, and reports were provided describing all the results of the analyses of each of the samples: Genotypes and frequencies are the predominant information derived from this system. The peaks were used to calculate the frequencies of SNP alleles.

\section{Results}

Of the 47 patients with AN analyzed, 33 were men (70.6\%) and 14 were women $(29.4 \%)$. The subjects' ages ranged from 2-61 years. The hearing loss, congenital in a total of 27 cases $(79.4 \%)$, began during childhood in three $(8.8 \%)$, and during adolescence in four $(11.8 \%)$, of the cases.

Molecular changes were tracked in all 34 patients who were involved in this study and three parents, and the results are shown in Table I.

The c.35delG mutation in the connexin 26 (GJB2) gene was found in the homozygous form in three patients, and in the heterozygous form in one of the parents of these cases. No other changes were identified in the GJB2 gene. Deletions in the GJB6 gene [del(GJB6-D13S1830) and del(GJB6-D13S1854)] were not identified in any of the subjects, and neither was the mutation m.1555A $>\mathrm{G}$ in mitochondrial gene, MTRNR1, detected in any case studied.

A subsequent project is track the other mutations in the OTOF gene through the complete sequencing of the 48 exons.
This process is already under development; however, thus far only four exons (exons 2, 3, 5 and 7) from certain patients have been analyzed. The partial results obtained are presented in Tables II and III. A total of 11 different genetic alterations were identified: Three exonic variations (Table II) and 8 intronic changes (Table III), all of which have been previously described in the literature.

Among the changes that were exonic were two silent variants, p.D43D (c.129C>T) in exon 2 and p.T124T (c.372A>G) in exon 5, and a missense mutation, p.A53V (c.158C $>\mathrm{T})$, in exon 3. The p.A53V and p.T124T variants are considered to be non-pathogenic polymorphisms, although p.D43D is likely not to be pathogenic, since it is a silent change $(29,54)$.

\section{Discussion}

Deafness is an etiologically heterogeneous trait with numerous known genetic and environmental causes, with genetic factors accounting for at least half of all cases of profound congenital deafness $(29,54)$. A study previously reported that the fraction of AN cases in a sample of individuals with non-syndromic hearing loss that are likely to be genetic is $\sim 70 \%$ in Brazil (34).

Genetic deafness can be classified by the mode of inheritance (dominant or recessive) and the presence or absence of characteristic clinical features that may be associated and allow the diagnosis of a specific form of syndromic deafness. Currently, the identification of $>120$ independent genes for deafness has provided profound novel insights into the pathophysiology of hearing, with recessive mutations at a single locus (the gene $G J B 2$, or connexin 26), accounting for more than half of all genetic cases in certain specific populations, such as in the example of familial non-syndromic hearing loss, and even $30 \%$ of sporadic cases $(55,56)$.

Knowing the mutation may allow the physician to make predictions regarding the progression of hearing loss or other abnormalities, although more efficient methods of genetic testing are required. These methods may allow the screening of all genetic mutations simultaneously. Therefore, the study of the genetic basis of $\mathrm{AN}$ is most important for a differential diagnosis, as well as for developing more specific treatments and more accurate genetic counseling.

Among the intronic changes identified were three polymorphisms considered non-pathogenic, IVS2+62C $>\mathrm{T}$, IVS3+55C $>$ T39IVS5 and A>T, and likely to be a non-pathogenic variant, IVS510A $>\mathrm{G}$. The other intronic variants, IVS2+28T $>$ G, IVS2+75G $>A$, IVS5-59T $>C$ and IVS7-39C $>$ T, are of unknown clinical significance; however, they are likely to have no relation to the clinical picture, since they are located, relatively, at a further distance from splicing sites.

Although, at present, $>80$ pathogenic mutations have been identified in the $O T O F$ gene in individuals with non-syndromic deafness in populations of different origins, there is no 'hot-spot' in this gene (28). However, all reported mutations are gathered in two regions, exon 13 to 30 and exon 35 to 48, which may explain the absence of pathogenic mutations in the present study, since only certain of the initial exons of the gene have been analyzed thus far (28).

In a Brazilian study, $>60 \%$ of cases with $\mathrm{AN}$ had at least one pathogenic mutation in the OTOF gene (34). Since muta- 
Table I. Molecular test results in patients and their parents. The genetic changes found are highlighted.

\begin{tabular}{|c|c|c|c|c|c|c|c|}
\hline \multirow[b]{2}{*}{ Subject } & \multicolumn{3}{|c|}{$G J B 2$ gene } & \multicolumn{2}{|c|}{ GJB6 gene } & \multirow{2}{*}{$\begin{array}{c}\begin{array}{c}M T R N R l \\
\text { gene }\end{array} \\
\text { m.1555A }>\mathrm{G}\end{array}$} & \multirow{2}{*}{$\begin{array}{c}\begin{array}{c}\text { OTOF } \\
\text { gene }\end{array} \\
\text { p.Q829X }\end{array}$} \\
\hline & $\begin{array}{l}\text { AS-PCR } \\
\text { c.35delG }\end{array}$ & IVS $1+1 G>A$ & $\begin{array}{c}\text { Sequencing } \\
\text { allele 1/allele } 2\end{array}$ & $\begin{array}{l}\text { del }(G J B 6- \\
\text { D13S1830) }\end{array}$ & $\begin{array}{l}\text { del (GJB6- } \\
\text { D13S1854) }\end{array}$ & & \\
\hline 1 & WT & WT & WT & WT & WT & WT & WT \\
\hline 2 & WT & WT & WT & WT & WT & WT & WT \\
\hline 3 & 35delG/35delG & WT & 35delG/35delG & WT & WT & WT & WT \\
\hline 4 & $\mathrm{WT}$ & WT & WT & WT & WT & WT & WT \\
\hline 5 & WT & WT & WT & WT & WT & WT & WT \\
\hline 6 & WT & WT & WT & WT & WT & WT & WT \\
\hline 7 & WT & WT & WT & WT & WT & WT & WT \\
\hline 7 (b) & WT & WT & WT & WT & WT & WT & WT \\
\hline 8 & WT & WT & WT & WT & WT & WT & WT \\
\hline 9 & WT & WT & WT & WT & WT & WT & WT \\
\hline 10 & WT & WT & WT & WT & WT & WT & WT \\
\hline 11 & WT & WT & WT & WT & WT & WT & WT \\
\hline 12 & WT & WT & WT & WT & WT & WT & WT \\
\hline 13 & WT & WT & WT & WT & WT & WT & WT \\
\hline 14 & WT & WT & WT & WT & WT & WT & WT \\
\hline 15 & WT & WT & WT & WT & WT & WT & WT \\
\hline 16 & WT & WT & WT & WT & WT & WT & WT \\
\hline 17 & WT & WT & WT & WT & WT & WT & WT \\
\hline 18 & WT & WT & WT & WT & WT & WT & WT \\
\hline 19 & WT & WT & WT & WT & WT & WT & WT \\
\hline 20 & WT & WT & WT & WT & WT & WT & WT \\
\hline 21 & WT & WT & WT & WT & WT & WT & WT \\
\hline 22 & WT & WT & WT & WT & WT & WT & WT \\
\hline 23 & WT & WT & WT & WT & WT & WT & WT \\
\hline 24 & WT & WT & WT & WT & WT & WT & WT \\
\hline 25 & WT & WT & WT & WT & WT & WT & WT \\
\hline 26 & WT & WT & WT & WT & WT & WT & WT \\
\hline 27 & WT & WT & WT & WT & WT & WT & WT \\
\hline 28 & WT & WT & WT & WT & WT & WT & WT \\
\hline 29 & WT & WT & WT & WT & WT & WT & WT \\
\hline 30 & $35 \mathrm{delG} / 35 \mathrm{delG}$ & WT & 35delG/35delG & WT & WT & WT & WT \\
\hline 31 & WT & WT & WT & WT & WT & WT & WT \\
\hline 32 & WT & WT & WT & WT & WT & WT & WT \\
\hline 33 & WT & IVS1+1G>A/WT & WT & WT & WT & WT & WT \\
\hline 34 & WT & WT & V153I/WT & WT & WT & WT & WT \\
\hline 35 & WT & WT & WT & WT & WT & WT & WT \\
\hline 36 & WT & WT & WT & WT & WT & WT & WT \\
\hline 37 & WT & WT & WT & WT & WT & WT & WT \\
\hline 38 & WT & WT & WT & WT & WT & WT & WT \\
\hline 39 & WT & WT & WT & WT & WT & WT & WT \\
\hline 40 & WT & WT & WT & WT & WT & WT & WT \\
\hline 41 & WT & WT & WT & WT & WT & WT & WT \\
\hline 42 & WT & WT & WT & WT & WT & WT & WT \\
\hline 43 & WT & WT & WT & WT & WT & WT & WT \\
\hline 44 & WT & WT & WT & WT & WT & WT & WT \\
\hline 45 & 35delG/35delG & WT & 35delG/35delG & WT & WT & WT & WT \\
\hline 45 (f) & 35delG/WT & WT & 35delG/WT & WT & WT & WT & WT \\
\hline $45(\mathrm{~m})$ & 35delG/WT & WT & 35delG/WT & WT & WT & WT & WT \\
\hline
\end{tabular}


Table I. Continued.

\begin{tabular}{|c|c|c|c|c|c|c|c|}
\hline \multirow[b]{2}{*}{ Subject } & \multicolumn{3}{|c|}{ GJB2 gene } & \multicolumn{2}{|c|}{ GJB6 gene } & \multirow{2}{*}{$\begin{array}{c}\begin{array}{c}M T R N R l \\
\text { gene }\end{array} \\
\mathrm{m} .1555 \mathrm{~A}>\mathrm{G}\end{array}$} & \multirow{2}{*}{$\begin{array}{c}\begin{array}{c}\text { OTOF } \\
\text { gene }\end{array} \\
\text { p.Q829X }\end{array}$} \\
\hline & $\begin{array}{l}\text { AS-PCR } \\
\text { c.35delG }\end{array}$ & IVS1+1G $>A$ & $\begin{array}{c}\text { Sequencing } \\
\text { allele 1/allele } 2\end{array}$ & $\begin{array}{l}\text { del (GJB6- } \\
\text { D13S1830) }\end{array}$ & $\begin{array}{l}\text { del (GJB6- } \\
\text { D13S1854) }\end{array}$ & & \\
\hline 45 (b) & 35delG/WT & WT & $35 \mathrm{delG} / \mathrm{WT}$ & WT & WT & WT & WT \\
\hline 46 & WT & WT & WT & WT & WT & WT & WT \\
\hline 47 & WT & WT & WT & WT & WT & WT & WT \\
\hline
\end{tabular}

AS-PCR, allele-specific polymerase chain reaction; WT, wild-type; $b$, brother; $f$, father; $\mathrm{m}$, mother.

Table II. Summary of exonic changes identified to date in the $O T O F$ gene.

\begin{tabular}{llcll}
\hline Exon & \multicolumn{1}{c}{ Finding } & Frequency & \multicolumn{1}{c}{ Genotype } & \multicolumn{1}{c}{ Clinical outcomes } \\
\hline 2 & p.D43D $(\mathrm{c} .129 \mathrm{C}>\mathrm{T})$ & $1 / 21$ & Heterozygosity & Probably non-pathogenic \\
3 & p.A53 $\mathrm{V}(\mathrm{c} .158 \mathrm{C}>\mathrm{T})$ & $2 / 15$ & Heterozygosity & Non-pathogenic \\
5 & p.T124T $(\mathrm{c} .372 \mathrm{~A}>\mathrm{G})$ & $5 / 20$ & Heterozygosity and homozygous & Nonpathogenic \\
\hline
\end{tabular}

Table III. Summary of intronic changes identified to date in the OTOF gene.

\begin{tabular}{llcll}
\hline Intron & \multicolumn{1}{c}{ Finding } & Frequency & \multicolumn{1}{c}{ Genotype } & \multicolumn{1}{c}{ Clinical outcomes } \\
\hline 2 & IVS2+28T $>\mathrm{G}$ & $1 / 21$ & Heterozygosity & Unknown \\
& IVS2+62C $>\mathrm{T}$ & $1 / 21$ & Heterozygosity & Non-pathogenic \\
& IVS2+75G $>\mathrm{A}$ & $1 / 21$ & Heterozygosity & Unknown \\
3 & IVS3+55C $>\mathrm{T}$ & $14 / 15$ & Heterozygosity and homozygous & Non-pathogenic \\
4 & IVS5-59T>C & $1 / 20$ & Heterozygosity & Unknown \\
5 & IVS5+10A $>\mathrm{G}$ & $1 / 20$ & Heterozygosity & Probably non-pathogenic \\
& IVS5+39A $>\mathrm{T}$ & $13 / 20$ & Heterozygosity and homozygous & Non-pathogenic \\
6 & IVS7-39C $>\mathrm{T}$ & $3 / 5$ & Heterozygosity & Unknown \\
\hline
\end{tabular}

tions in this gene are a frequent cause of $\mathrm{AN}$ in this population, a large number of individuals with a genetic etiology would be expected to be found in our sample resulting from mutations especially in the OTOF gene.

AN is characterized by absent or abnormal auditory brainstem responses and preserved otoacoustic emissions and/or cochlear microphonics (57). It is estimated that the prevalence of AN ranges between 0.23 and $15 \%$ in individuals with hearing loss, although it may vary according to the different criteria of patient inclusion and/or methodology. A previous study in Brazil identified AN in $1.2 \%$ of the patients with sensorineural hearing loss $(n=2.292)$ in an auditory health care service (58).

Various studies have shown that patients with AN are heterogeneous in their underlying etiology, age and clinical manifestation, and patients may range from newborns to adults (57). AN may be caused by a variety of environmental and genetic factors. Approximately $40 \%$ of AN cases may have a genetic etiology $(20,22)$.
Another study demonstrated that $\mathrm{AN}$ was associated with hereditary neurological disorders in $42 \%$ of the patients; in $10 \%$ of the patients, it was associated with toxic, metabolic, immunological and infectious causes; while the cause was unknown in $48 \%$ of patients (20-22). Most cases with AN are sporadic, although researchers have identified a number of familial cases with two or more affected members. Mutations may occur, for example, substitutions, deletions or base-pair insertions, although familial cases suggest that $\mathrm{AN}$ is inherited in certain genetic inheritance patterns (59).

To date, four loci associated with non-syndromic AN have been mapped: DFNB9 (the OTOF gene) and DFNB59 (the $P J V K$ gene), which are responsible for the autosomal recessive pattern; AUNA1 (DIAPH3 gene) for autosomal dominant; and AUNX1 for X-linked (23,24,26,32,33).

AUNAl was first cited by Kim et al (30), when the first gene found in a four generation family was reported to be responsible for non-syndromic, autosomal dominant AN. The linkage analysis revealed an association with a novel section 
of DNA on chromosome 13q14-21, between the D13S153 and D13S1317 markers (30). In addition, mutations in the connexin 26 (GJB2) and mitochondrial 12S rRNA genes were also reported in subjects with AN $(37,60)$.

Molecular diagnosis is complicated by the extensive genetic heterogeneity. The GJB2 gene, and GJB6 mutations encoding connexins 26 and 30, in the DFNB1 locus are responsible for $>50 \%$ of all cases of autosomal recessive hearing loss. However, the contribution of other gene mutations continues to be investigated, and this research is complicated by the evidence that the genetic epidemiology of non-syndromic hearing loss is highly variable among populations $(13,14,40,52,61,62)$.

The $O T O F$ gene is located on chromosomal region 2p22-23 $(2,23,26)$. This gene encodes OTOF, a membrane calcium-binding protein involved in vesicle membrane fusion that serves a role in the exocytosis of synaptic vesicles at the auditory inner hair cell ribbon synapse $(23,26)$. OTOF is expressed in the cochlea, vestibule and brain $(23,26,34)$. The currently available data suggest that mutations in OTOF are a major cause of AN in a number of populations, with $>100$ identified pathogenic mutations, as revealed in the Human Gene Mutation Database (29,63-65).

Genetic research has shown that mutations in the $O T O F$ gene are associated with non-syndromic autosomal recessive AN (57). Most OTOF mutations are exclusive, each being reported in only one family. One notable exception is p.Q829X (c.2485C $>\mathrm{T}$ ) and in the present study, the p.Q829X mutation was investigated in the OTOF gene, although it had not been identified previously in any of the patients $(2,27)$. The p.Q829X mutation is the most frequent mutation of the OTOF gene, and the third most common cause of non-syndromic autosomal recessive hearing loss in the Spanish population $(29,52)$, the second in French and Argentine populations $(2,66)$, and the first in Mexican and English populations $(2,26)$. However, it is not a common cause of deafness in the Brazilian population $(34,67-69)$.

The PJVK gene is mapped to chromosome 2q31.1-q31.3, and encodes PJVK, a 352-residue protein of unknown function, which is possibly associated with the activity of neurons or hair cells. PJVK is expressed in the body cells of all spiral ganglion neurons. Little is known about its contribution to the total of AN cases with genetic origin $(33,66)$.

Researchers consider that PJVK is crucial for auditory nerve signaling. A missense mutation in DFNB59 would result in the production of a protein other than PJVK, resulting in $\mathrm{AN}$ due to a disruption in neuronal signaling along the auditory pathway (57).

In 2004, the AUNA1 locus was mapped in an American pedigree, on chromosomal region 13q14-21, associated with post-lingual AN. The corresponding gene, DIAPH3, was later identified. No information is currently available about precise expression patterns of the DIAPH3 gene or the localization of DIAPH3 within the inner ear. The function of DIAPH3 in the cochlea remains uncertain $(30,31)$.

Wang et al (64) mapped the AUNX1 locus on chromosomal region Xq23-q27.3 in a Chinese pedigree, although the corresponding gene has yet to be identified $(64,69)$.

There are only two studies that have reported GJB2 mutations in patients with AN. This gene is expressed in cochlear non-sensory supporting cells, and encodes the connexin 26 protein, which is associated with cell communication (gap junctions), forming channels that mediate the passage of small ions and molecules across cell membranes $(35,36)$.

Connexin 26 deficiency disrupts the inner ear ion homeostasis, which leads to a local extracellular accumulation of potassium and cell death. Conversely, it is hypothesized that it may cause impairment of inner hair cells and nerve endings under the hair cells, and may be responsible for non-syndromic recessive AN. Therefore, it has not been established whether pathogenic variants in connexin 26 may be involved with AN, or whether the otoacoustic emissions that were recorded in the patients only represent the residual activity of a few outer hair cells that remain alive in the apical part of the cochlea. However, it is considered that certain mutations in the GJB2 gene may cause changes in the inner hair cells and nerve endings of hair cells. Further investigation is needed to clarify the link between $G J B 2$ mutations and AN $(37,38,70)$.

It has also been reported that mutations in the GJB6 and GJB3 genes contribute to autosomal recessive and autosomal dominant hearing defects in a number of populations. Mutations within the connexin GJB3 gene family are considered to be the next most frequent cause of non-syndromic hearing defects, associated with non-syndromic autosomal dominant hearing impairment $(38,54)$.

Mitochondrial mutations are associated with aminoglycoside-induced hearing loss, and also with maternally inherited non-syndromic hearing loss without exposure to aminoglycosides. One of these mutations, m.1095T $>C$ in the mitochondrial $12 \mathrm{~S}$ rRNA gene, was originally identified in two Italian families, and later in several Chinese families. However, the phenotypic differences observed among the subjects suggest that the mutation may be not actually responsible for the clinical signs. The identification and the clinical and molecular characterization of novel cases may elucidate its association with AN (70-72).

In addition, $\mathrm{AN}$ associated with mitochondrial disease may also be associated with hereditary syndromes, including Charcot-Marie-Tooth disease, Leber's hereditary optic neuropathy, autosomal dominant optic atrophy, autosomal recessive optic atrophy, Fredreich's ataxia, Mohr-Tranebjaerg syndrome and Refsum's disease with different inheritance types: Autosomal recessive, autosomal dominant, $\mathrm{X}$-linked recessive and mitochondrial. Peripheral neuropathies may also be associated with neuronal nitric oxide synthase gene deficiency $(57,73)$.

Ongoing research aims to identify other genes that are associated with AN. With this knowledge, an improved understanding of the underlying pathophysiological basis may be acquired, and specific treatments can be developed since, once a gene responsible has been identified, the protein it encodes and the target of treatment may be determined. This is a possible explanation of the heterogeneity of the disease and the different responses of patients to an identical treatment (56).

$\mathrm{AN}$ is a challenging condition, as numerous factors concerned with its etiology and pathogenesis remain poorly understood. Additionally, studies are needed to provide an improved understanding and clarification of AN. Further studies, particularly in the fields of molecular and genetic research, are required, in addition to the oncology research field (74). The study of the genetic basis of AN is therefore 
important to improve the diagnosis, management, therapy and genetic counseling of the affected subjects.

In conclusion, in the present study, three homozygous c.35delG deletions were detected in patients with AN. In the OTOF gene, 11 mutations were identified, , although they are likely to be non-pathogenic, and the majority have a heterozygous genotype. However, the associations between these mutations and their correlation with AN have yet to be fully elucidated, and further studies are required to improve on the understanding of the pathophysiology of AN.

\section{Acknowledgements}

The present study, including the protocols for subject recruitment and assessment, the informed consent for participants, and the overall analysis plan were reviewed and approved by the Faculty of Medical Sciences-UNICAMP and the Center for Molecular Biology and Engineering (CBMEG), São Paulo, Brazil, by their doctoral programs and research ethics committees. The authors would also like to thank their University, their Department, their patients and every person who supported them in performing their research. This article is part of a doctoral project that is funded by CAPES (Higher Education Personnel Improvement Coordination, Ministry of Health, Brazil). The authors would like to thank to the Institutional Support from CNPq (National Council for Scientific and Technological Development, National Counsel of Technological and Scientific Development, Politec Saúde and Cochlear Brazil/LA).

\section{References}

1. Dror AA and Avraham KB: Hearing loss: Mechanisms revealed by genetics and cell biology. Annu Rev Genet 43: 411-437, 2009.

2. Rodríguez-Ballesteros M, Reynoso R, Olarte M, Villamar M, Morera C, Santarelli R, Arslan E, Medá C, Curet C, Völter C, et al: A multicenter study on the prevalence and spectrum of mutations in the otoferlin gene (OTOF) in subjects with nonsyndromic hearing impairment and auditory neuropathy. Hum Mutat 29 823-831, 2008.

3. Pupo AC, Balieiro CR and Figueire do RSL: Retrospective study of hearing impaired children and teenager: Characterizing the etiologies and audiologic aspects. Rev CEFAC 10: 84-91, 2008.

4. Calháu CM, Lima-Júnior LR, Reis AM, Capistrano AK, Lima Ddo V, Calháu AC and Rodrigues Júnior Fde A: Etiology profile of the patients implanted in the cochlear implant program. Braz J Otorhinolaryngol 77: 13-18, 2011 (In Portuguese).

5. Tekin M, Arnos KS and Pandya A: Advances in hereditary deafness. Lancet 358: 1082-1090, 2001.

6. Schrijver I: Hereditary non-syndromic sensorineural hearing loss: Transforming silence to sound. J Mol Diagn 6: 275-284, 2004.

7. Piatto VB and Maniglia JV: Importância do gene conexina 26 na etiologia da deficiência auditiva sensorioneural não-sindrômica. Acta Awho 20: 106-112, 2001.

8. Simões AM and Maciel-Guerra AT: A surdez evitável: Predominância de fatores ambientais na etiologia da surdez neurossensorial profunda. J pediatr 68: 254-257, 1992

9. Stöver T and Diensthuber M: Molecular biology of hearing. Laryngorhinootologie 90 (Suppl 1): S22-S34, 2011 (In German).

10. Wilcox ER and Fex J: Construction of a cDNA library from microdissected guinea pig organ of Corti. Hear Res 62: 124-126, 1992.

11. Robertson NG, Khetarpal U, Gutiérrez-Espeleta GA, Bieber FR and Morton CC: Isolation of novel and known genes from a human fetal cochlear cDNA library using subtractive hybridization and differential screening. Genomics 23: 42-50, 1994.

12. Heller S, Sheane CA, Javed Z and Hudspeth AJ: Molecular markers for cell types of the inner ear and candidate genes for hearing disorders. Proc Natl Acad Sci USA 95: 11400-11405, 1998.
13. Hilgert N, Smith RJH and Van Camp G: Function and expression pattern of nonsyndromic deafness genes. Curr Mol Med 9: 546-564, 2009.

14. Hilgert N, Smith RJ and Van Camp G: Forty-six genes causing nonsyndromic hearing impairment: Which ones should be analyzed in DNA diagnostics? Mutat Res 681: 189-196, 2009.

15. Friedman RA, Bykhovskaya Y, Sue CM, DiMauro S, Bradley R, Fallis-Cunningham R, Paradies N, Pensak ML, Smith RJ, Groden $\mathrm{J}$, et al: Maternally inherited nonsyndromic hearing loss. Am J Med Genet 84: 369-372, 1999.

16. Smith RJH, Hilderbrand MS and Van Camp G: 1993. Deafness and hereditary hearing loss overview. In: Pagon RA, Bird TD, Dolan CR, Stephens K. (Eds). Gene reviews (http://www.ncbi. nlm.nih.gov/books/NBK1434/). Accessed 25 November 2011, Seattle: University of Washington, Washington.

17. Kokotas H, Petersen MB and Willems PJ: Mitochondrial deafness. Clin Genet 71: 379-391, 2007.

18. Van Camp G and Smith RJH: 2014. Hereditary Hearing Loss Homepage (http://hereditaryhearingloss.org), accessed 25 March 2012, Belgium.

19. Starr A, Picton TW, Sininger YS, Hood LJ and Berlin CI: Auditory neuropathy. Brain 119: 741-753, 1996.

20. Sininger YS: Identification of auditory neuropathy in infants and children. Semin Hear 23: 193-200, 2002.

21. Rance G: Auditory neuropathy/dys-synchrony and its perceptual consequences. Trends Amplif 9: 1-43, 2005.

22. Starr A, Sininger YS and Pratt H: The varieties of auditory neuropathy. J Basic Clin Physiol Pharmacol 11: 215-230, 2000.

23. Yasunaga S, Grati M, Cohen-Salmon M, El-Amraoui A, Mustapha M, Salem N, El-Zir E, Loiselet J and Petit C: A mutation in OTOF, encoding otoferlin, a FER-1 like protein, causes DFNB9, a nonsyndromic form of deafness. Nat Genet 21: 363-369, 1992

24. Chaib H, Place C, Salem N, Chardenoux S, Vincent C, Weissenbach J,El-Zir E, Loiselet J and Petit C: A gene responsible for a sensorineural nonsyndromic recessive deafness maps to chromosome 2p22-23. Hum Mol Genet 5: 155-158, 1996.

25. Roux I, Safieddine S, Nouvian R, Grati M, Simmler MC, Bahloul A, Perfettini I, Le Gall M, Rostaing P, Hamard G, et al: Otoferlin, defective in a human deafness form, is essential for exocytosis at the auditory ribbon synapse. Cell 127: 277-289, 2006.

26. Yasunaga S, Grati M, Chardenoux S, Smith TN, Friedman TB, Lalwani AK, Wilcox ER and Petit C: OTOF encodes multiple long and short isoforms: Genetic evidence that the long ones underlie recessive deafness DFNB9. Am J Hum Genet 67: 591-600, 2000.

27. Rodríguez-Ballesteros M, del Castillo FJ, Martín Y, Moreno-Pelayo MA, Morera C, Prieto F, Marco J, Morant A, Gallo-Terán J, Morales-Angulo C, et al: Auditory neuropathy in patients carrying mutations in the otoferlin gene (OTOF). Hum Mutat 22: 451-456, 2003.

28. Mahdieh N, Shirkavand A, Rabbani B, Tekin M, Akbari B, Akbari MT and Zeinali S: Screening of OTOF mutations in Iran: A novel mutation and review. Int J Pediatr Otorhinolaryngol 76: 1610-1615, 2012.

29. Varga R, Avenarius MR, Kelley PM, Keats BJ, Berlin CI, Hood LJ, Morlet TG, Brashears SM, Starr A, Cohn ES, et al: OTOF mutations revealed by genetic analysis of hearing loss families including a potential temperature sensitive auditory neuropathy allele. J Med Genet 43: 576-581, 2006.

30. Kim TB, Isaacson B, Sivakumaran TA, Starr A, Keats BJ and Lesperance MM: A gene responsible for autosomal dominant auditory neuropathy (AUNA1) maps to 13q14-21. J Med Genet 41: $872-876,2004$.

31. Schoen CJ, Emery SB, Thorne MC, Ammana HR, Sliwerska E, Arnett J, Hortsch M, Hannan F, Burmeister $M$ and Lesperance MM: Increased activity of Diaphanous homolog 3 (DIAPH3)/diaphanous causes hearing defects in human with auditory neuropathy and in Drosophila. Proc Natl Acad Sci USA 107: 13396-13401, 2010.

32. Wang QJ, Li QZ, Rao SQ, Lee K, Huang XS, Yang WY, Zhai SQ, Guo WW, Guo YF, Yu N, et al: AUNX1, a novel locus responsible for $\mathrm{X}$ linked recessive auditory and peripheral neuropathy, Maps to Xq23-27.3. J Med Genet 43: e33, 2006.

33. Delmaghani S, del Castillo FJ, Michel V, Leibovici M, Aghaie A, Ron U, Van Laer L, Ben-Tal N, Van Camp G, Weil D, et al: Mutations in the gene encoding pejvakin, a newly identified protein of the afferent auditory pathway, cause DFNB59 auditory neuropathy. Nat Genet 38: 770-778, 2006. 
34. Romanos J, Kimura L, Fávero ML, Izarra FA, de Mello Auricchio MT, Batissoco AC, Lezirovitz K, Abreu-Silva RS and Mingroni-Netto RC: Novel OTOF mutations in Brazilian patients with auditory neuropathy. J Hum Genet 54: 382-385, 2009.

35. Cheng X, Li L, Brashears S, Morlet T, Ng SS, Berlin C, Hood L and Keats B: Connexin 26 variants and auditory neuropathy/dys-synchrony among children in schools for the deaf. Am J Med Genet 139: 13-18, 2005.

36. Santarelli R, Cama E, Scimemi P, Dal Monte E, Genovese E and Arslan E: Audiological and electrocochleography findings in hearing-impaired children with connexin 26 mutations and otoacoustic emissions. Eur Arch Otorhinolaryngol 265: 43-51, 2008

37. Matsunaga T: Trends in genetic research on auditory neuropathy. In: Kaga K, Starr A (Eds). Neuropathies of the Auditory and Vestibular Eight Cranial Nerves. Tokio: Springer, pp 43-50, 2009.

38. Del Castillo FJ and Del Castillo I: Genetics of isolated auditory neuropathies. Front Biosci (Landmark Ed) 17: 1251-1265, 2012.

39. Li TC, Wang WH, Li C and Yang JJ: Association between mutations in the gap junction $\beta 4$ gene and nonsyndromic hearing loss: Genotype-phenotype correlation patterns. Mol Med Rep 11 619-624, 2015.

40. Gut IG. 2002. SNP genotyping by MALDI mass spectrometry. In Gut IG; Lathrop M; Weeks D (Eds). Methods for the elucidation of genomic variation. Ateliers de formation-INSERM. La Roche Posay: pp 2-3.

41. Oberacher H: On the use of different mass spectrometric techniques for characterization of sequence variability in genomic DNA. Anal Bioanal Chem 391: 135-149, 2008.

42. Karas M and Hillenkamp F: Laser desorption ionization of proteins with molecular masses exceeding 10,000 daltons. Anal Chem 60: 2299-2301, 1988 .

43. Griffin TJ and Smith LM: Single-nucleotide polymorphism analysis by MALDI-TOF mass spectrometry. Trends Biotechnol 18: 77-84, 2000

44. Scott DA, Kraft ML, Carmi R, Ramesh A, Elbedour K, Yairi Y, Srisailapathy CR, Rosengren SS, Markham AF, Mueller RF, et al: Identification of mutations in the connexin 26 gene that cause autosomal recessive nonsyndromic hearing loss. Hum Mutat 11: 387-394, 1998

45. Irwin D: 2008. The MASSARRAY System for Plant Genomics In: Henry RJ, Ed. Plant Genotyping II SNP Technology. CABI Publishing, p285.

46. Moore DD and Dowhan D: Preparation and analysis of DNA. Curr Protoc Mol Biol 58: 21.1-2.1.3, 2002.

47. Baris I, Koksal V and Etlik O: A combined allele-specific PCR and RFLP assay to detect the $35 \mathrm{delG}$ Mutation in the 26 gene. Genet Test 8: 384-386, 2004.

48. Denoyelle F, Weil D, Maw MA, Wilcox SA, Lench NJ, Allen-Powell DR, Osborn AH, Dahl HH, Middleton A, Houseman MJ, et al: Prelingual deafness: High prevalence of a 30delG mutation in the connexin 26 gene. Hum Mol Genet 6 : 2173-2177, 1997

49. Kelsell DP, Dunlop J, Stevens HP, Lench NJ, Liang JN, Parry G, Mueller RF and Leigh IM: Connexin 26 mutations in hereditary non-syndromic sensorineural deafness. Nature 387: 80-83, 1997.

50. Del Castillo I, Moreno-Pelayo MA, Del Castillo FJ, Brownstein Z, Marlin S, Adina Q, Cockburn DJ, Pandya A, Siemering KR, Chamberlin GP, et al: Prevalence and evolutionary origins of the del (GJB6-D13S1830) mutation in the DFNB1 locus in hearing impairment subjects: A multicenter study. Am J Hum Genet 73: $1452-1458,2003$

51. Del Castillo FJ, Rodríguez-Ballasteros M, Alvares A, Hutchin T, Leonardi E, de Oliveira CA, Azaiez H, Brownstein Z, Avenarius MR, Marlin S, et al: A novel deletion involving the connexin 30 gene del(GJB6-D13S1854), found in trans with mutations in the GJB2 gene (connexin 26) in subjects with DFNB1 non-syndromic hearing impairment. J Med Genet 42: 588-594, 2005.

52. Friedman TB and Griffith AJ: Human nonsyndromic sensorineural deafness. Ann Rev Genomics Hum Genet 4: 341-402, 2003

53. Iwasaki S, Tamagawa Y, Ocho S, Hoshino T and Kitamura K: Hereditary sensorineural hearing loss of unknown cause involving mitochondrial DNA A1555 mutation. ORL J Otorhinolaryngol Relat Spec 62: 100-103,2000.

54. Migliosi V, Modamio-Høybjør S, Moreno-Pelayo MA, Rodríguez-Ballesteros M, Villamar M, Tellería D, Menéndez I, Moreno F and Del Castillo I: Q829X, a novel mutation in the gene encoding otoferlin (OTOF), is frequently found in Spanish patients with prelingual non-syndromic hearing loss. J Med Genet 39: 502-506, 2002.
55. Nahili H, Ridal M, Boulouiz R, Abidi O, Imken L, Rouba H, Alami MN, Chafik A, Hassar M and Barakat A: Absence of GJB3 and GJB6 mutations in Moroccan familial and sporadic patients with autosomal recessive non-syndromic deafness. Int J Pediatr Otorhinolaryngol 72: 1633-1636, 2008.

56. Nancy WE: The genetics of deafness. Ment Retard Dev Disabil Res Rev 9: 109-119, 2003.

57. Nikolopoulos TP: Auditory dyssynchrony or auditory neuropathy: Understanding the pathophysiologyand exploring methods of Treatment. Int J Pediatr Otorhinolaryngol 78: 171-173, 2014.

58. Penido R and Isaac ML: Prevalence of auditory neuropathy spectrum disorder in an auditory health care service. Braz J Otorhinolaryngol 79: 429-433, 2013 (In English, Portuguese).

59. Manchaiah VK, Zhao F, Danesh AA and Duprey R: The genetic basis of auditory neuropathy spectrum disorder (ANSD). Int J Pediatr Otorhinolaryngol 75: 151-158, 2011

60. Cohen-Salmon M, Ott T, Michel V, Hardelin JP, Perfettini I, Eybalin M, Wu T, Marcus DC, Wangemann P, Willecke K and Petit C: Targeted ablation of connexin26 in the inner ear epithelial gap junction network causes hearing impairment and cell death. Curr Biol 12: 1106-1111,2002.

61. Petit C, Levilliers J and Hardelin JP: Molecular genetics of hearing loss. Annu Rev Genet 35: 589-646, 2001

62. Petersen $M B$ and Willems PJ: Non-syndromic, autossomal-recessive deafness. Clin Genet 69: 371-392, 2006

63. Chiu YH, Wu CC, Lu YC, Chen PJ, Lee WY, Liu AY and Hsu CJ: Mutations in the OTOF gene in Taiwanese patients with auditory neuropathy. Audiol Neurootol 15: 364-374, 2010.

64. Wang QJ, Wang YC, Weil D, Zhao YL, Rao SQ, Zong L, Ji YB, Liu Q, Li JQ, Yang HM, et al: Screening mutations of OTOF gene in Chinese patients with auditory neuropathy, including a familial case of temperature-sensitive auditory neuropathy. BMC Med Genet 11: 79, 2010.

65. Cooper DN, Ball EV, Stenson PD, Phillips AD, Howells K, Heywood S, et al: 2014. The Human Gene Mutation Database. Institute of Medical Genetics (Avalilable: http://www.hgmd.cf.ac. uk/ac/index.php), accessed 25 January 2014. Cardiff University, Cardiff.

66. Liu W, Kinnefors A, Boström M, Edin F and Rask-Andersen H: Distribution of pejvakin in human spiral ganglion: An immunohistochemical study. Cochlear Implants Int 14: 225-231, 2013.

67. Reynoso RA, Hendi S, Barteik ME, Curet CA, Nicemboin L, Moreno Barral J, Rodríguez Ballesteros M, Del Castillo I and Moreno F: Genetic study of hearing loss in families from Argentina. Rev Fac Cien Med Univ Nac Cordoba 61: 13-19, 2004 (In Spanish)

68. Rouillon I, Marcolla A, Roux I, Marlin S, Feldmann D, Couderc R, Jonard L, Petit C, Denoyelle F, Garabédian EN and Loundon N: Results of cochlear implantation in two children with mutations in the OTOF gene. Int J Pediatr Otohinolaryngol 70: 689-696, 2006.

69. Oliveira CA, Alexandrino F, Christiani TV, Steiner CE, Cunha JL, Guerra AT and Sartorato EL: Molecular genetics study of deafness in Brazil: 8-year experience. Am J Med Genet A 143A: 1574-1579, 2007.

70. Thyagarajan D, Bressman S, Bruno C, Przedborski S, Shanske S, Lynch T, Fahn S and DiMauro S: A novel mitochondrial 12SrRNA point mutation in parkinsonism, deafness and neuropathy. Ann Neurol 48: 730-736, 2000

71. Wang Q, Li R, Zhao H, Peters JL, Liu Q, Yang L, Han D, Greinwald JH Jr, Young WY and Guan MX: Clinical and molecular characterization of a Chinese patient with auditory neuropathy associated with mitochondrial 12S rRNA T1095C mutation. Am J Med Genet A 133A: 27-30, 2005.

72. Tessa A, Giannotti A, Tieri L, Vilarinho L, Marotta G and Santorelli FM: Maternally inherited deafness associated with a T1095C mutation in the mDNA. Eur J Hum Genet 9: 147-149, 2001.

73. Vareniuk I, Pacher P, Pavlov IA, Drel VR and Obrosova IG: Peripheral neuropathy in mice with neuronal nitric oxide synthase gene deficiency. Int J Mol Med 23: 571-580, 2009.

74. Pavlopoulou A, Spandidos DA and Michalopoulos I: Human cancer databases (review). Oncol Rep 33: 3-185, 2015. 